Biochem Biophys Res Commun. 2012 June 1; 422(2): 224-228. doi:10.1016/j.bbrc.2012.04.124.

\title{
O-GIcNAcylation of Kinases
}

\author{
Wagner B. Dias ${ }^{1}$, Win D. Cheung, and Gerald W. Hart \\ Department of Biological Chemistry, Johns Hopkins University, School of Medicine, Baltimore, \\ Maryland 21205, USA.
}

\begin{abstract}
Recent evidence indicates that site-specific crosstalk between $O$-GlcNAcylation and phosphorylation and the $O$-GlcNAcylation of kinases play an important role in regulating cell signaling. However, relatively few kinases have been analyzed for $O$-GlcNAcylation. Here, we identify additional kinases that are substrates for $O$-GlcNAcylation using an in vitro OGT assay on a functional kinase array. Forty-two kinases were $O$-GlcNAcylated in vitro, representing $39 \%$ of the kinases on the array. In addition, we confirmed the in vivo $O$-GlcNAcylation of three identified kinases. Our results suggest that $O$-GlcNAcylation may directly regulate a substantial number of kinases and illustrates the increasingly complex relationship between $O$-GlcNAcylation and phosphorylation in cellular signaling.
\end{abstract}

\section{Keywords \\ $O$-GlcNAcylation; phosphorylation; protein array; kinases; OGT; signaling}

\section{Introduction}

A hallmark of signal transduction is the dynamic inducible post-translational modification (PTM) of proteins. The most well-studied and understood regulatory PTM is phosphorylation. However, PTM of cytoplasmic and nuclear proteins at serine and threonine residues by $\beta$ - $N$-acetylglucosamine ( $O$-GlcNAc) has been emerging as a fundamental regulatory mechanism involved in cell signaling, metabolism, transcription, and cell division, among others[1,2]. $O$-GlcNAc cycling on proteins, mediated by the enzymes $O$ GlcNAc transferase (OGT) and $O$-GlcNAcase, is dynamically regulated in response to various stimuli and is remarkably similar to phosphorylation. $O$-GlcNAcylation has been detected on myriad proteins, including transcription factors, cytoskeleton proteins, histones, and signal transduction proteins, including a few kinases[3]. Like phosphorylation, $O$ GlcNAcylation can modulate protein function, including enzymatic activity (e.g. CaMKIV) [4], turnover (e.g. p53)[5], protein interactions (e.g. stat5)[6], subcellular localization (e.g. Sp1)[7], DNA affinity, and transcription activity (e.g. PDX-1)[8]. Deletion of OGT is lethal in mice at the embryonic level and at the single-cell level, highlighting the importance of $O$ GlcNAcylation in regulating basic cellular events[9]. Aberrant $O$-GlcNAcylation has been linked to major diseases, including diabetes, cancer, and Alzheimer's disease[10,11].

(C) 2012 Elsevier Inc. All rights reserved.

Address correspondence to: Gerald W. Hart, PhD, 725 N. Wolfe St., Baltimore, MD 21205-2185. Tel: 410-614-5993. Fax: 410-614-8804; gwhart@jhmi.edu.

${ }^{1}$ Present Address: Instituto de Biofisica Carlos Chagas Filho, UFRJ, CCS, Rio de Janeiro, Brazil, 21941-902. diaswb@biof.ufrj.br

Publisher's Disclaimer: This is a PDF file of an unedited manuscript that has been accepted for publication. As a service to our customers we are providing this early version of the manuscript. The manuscript will undergo copyediting, typesetting, and review of the resulting proof before it is published in its final citable form. Please note that during the production process errors may be discovered which could affect the content, and all legal disclaimers that apply to the journal pertain. 
Many papers have been published regarding the extensive interplay between $O$ GlcNAcylation and phosphorylation. Initial studies demonstrated that $O$-GlcNAc and phosphorylation mainly acted in opposing manners, suggesting a yin-yang relationship[12]. However, recent studies showed that the relationship between these PTMs is more complex than initially thought. Using proteomic approaches, Wang and colleagues[13] demonstrated that increased global $O$-GlcNAcylation, resulting from inhibition of $O$-GlcNAcase, concomitantly decreased a large number of phosphorylation events, as expected. However, $O$-GlcNAcase inhibition also led to an unexpected increase in phosphorylation at many other sites. These results suggest that $O$-GlcNAcylation and phosphorylation not only compete for substrates (at the same or proximal sites), but also that $O$-GlcNAcylation may also regulate phosphorylation cycling enzymes, such as kinases and/or phosphatases. Recently, $O$-GlcNAcylation was shown to directly regulate the kinase activity of CaMKIV toward CREB[4]. $O$-GlcNAcylation of Akt has been related to angiogenesis[14], apoptosis of murine pancreatic $\beta$-cells[15], and nuclear localization[16]. PKC isozymes are modified by $O$-GlcNAc, and PKCa activity seems to be regulated by this PTM[17]. It is our hypothesis that not only does phosphorylation regulate the O-GlcNAc cycling enzymes, but also that $O$-GlcNAcylation in-turn regulates the activity of many kinases. The human genome reveals that kinases represent about $2 \%$ of the genome[18], and until now, just a handful of kinases are described as $O$-GlcNAcylated. In addition, almost all $O$

GlcNAcylated proteins are also known to be phosphorylated, and kinases themselves are often regulated by phosphorylation. Taken together, these observations motivated us to screen for other kinases that may be $O$-GlcNAcylated.

Protein arrays have proven quite useful in research for screening protein activities, proteinligand or protein-drug interactions, among others[19]. Here, we used a functional human protein array containing 152 kinases as substrate for OGT in order to identify kinases that are $O$-GlcNAcylated in vitro. We identified 42 kinases that are $O$-GlcNAcylated in vitro, representing $39 \%$ of kinases analyzed. Of the 110 other kinases, 66 were not good substrates for OGT in vitro, while 44 others could not be analyzed due to low abundance or background issues. In addition, we confirmed the presence of $O$-GlcNAc on three of the kinases in vivo. These data provide a number of potential targets that may be regulated by $O$-GlcNAcylation and illustrates the increasingly complex relationship between $O$ GlcNAcylation and phosphorylation.

\section{Materials and Methods}

\subsection{OGT in vitro labeling}

The Panorama Human Kinase v1 Array (HPFM3 Sigma, Saint Louis, USA) was used as substrate for the in vitro OGT assay. This array contains a set of 152 full-length human kinases tagged with a biotin-carboxyl carrier protein (BCCP) and a c-Myc tag. First, the slides were blocked with $2 \%$ BSA in $50 \mathrm{mM}$ Tris-HCl, pH 7.2 (blocking buffer) for $20 \mathrm{~min}$. The prokaryotic expression vector encoding full-length human OGT[20] was a kind gift of Dr. Suzanne Walker (Harvard Medical School, Boston, MA). Human OGT was expressed and purified as described previously[21]. The in vitro OGT assay was performed on the array slides using $2 \mu \mathrm{g}$ of recombinant OGT and $10 \mu \mathrm{Ci}$ of UDP-[ $\left[{ }^{3} \mathrm{H}\right]-\mathrm{GlcNAc}$ in $120 \mu \mathrm{l}$ assay buffer (50 mM Tris-HCl, $\mathrm{pH} 7.2,0,1 \% \mathrm{BSA})$ covered with cover slips for $2 \mathrm{~h}$ at room temperature in a humid chamber. Subsequently, slides were washed with $0.5 \%$ NP-40 in assay buffer, followed by incubation with anti-c-Myc-Cy3 conjugate, as suggested by the manufacturer's instructions. The arrays were washed, dried, and scanned for $\mathrm{Cy} 3$ (Ex $550 \mathrm{~nm} / \mathrm{Em} 570 \mathrm{~nm}$ ) on a Typhoon 9400 laser scanner (GE Healthcare, Munich, Germany) to determine protein levels. Then, the slides were exposed to a ${ }^{3} \mathrm{H}$-sensitive storage phosphor screen (GE Healthcare, Munich, Germany) for one month. The storage phosphor screen was scanned on a Typhoon 9400 laser scanner, and the results were analyzed using Genepix Pro 
3.0 software (Molecular Devices Corporation, Sunnyvale, USA). We used several negative spots consisting of BCCP-Myc or beta-galactosidase-BCCP-Myc to normalize the amount of background ${ }^{3} \mathrm{H}$ labeling. We discarded the results of samples with anti-myc-Cy3 signals lower than the lowest negative control spot or when we observe background problems. We considered the sample to be valid only when all four replicate spots displayed the same trend. Kinases are defined as $O$-GlcNAcylated when exhibiting a signal greater than $150 \%$ of the $O$-GlcNAcylation signal/protein levels observed on negative controls. The $O$ GlcNAcylation levels (GL) were arbitrarily classified as very high (+++, GL > 3.0); high (+ $+, 3.0>\mathrm{GL}>2.0)$; or positive $(+, 2.0>\mathrm{GL}>1.5)$.

\subsection{Cell culture}

HEK293A cells were grown in Dulbecco's modified Eagle's medium (25 mM glucose; Mediatech) containing 10\% (v/v) fetal bovine serum (Gemini Bio-Products) and penicillin/ streptomycin (Mediatech). When indicated, cells were incubated with $10 \mu \mathrm{M} \mathrm{NAG-}$ thiazoline overnight before harvesting.

\subsection{Plasmids and cell transfection}

HEK293A cells were transfected with plasmid DNA using Lipofectamine 2000 (Invitrogen) according to the manufacturer's instructions. The human ERK-5 and S6LK cDNAs were obtained from the ATCC and subcloned into the pEF-HA mammalian expression plasmid[22]. The PKC- $\zeta$-Flag mammalian expression plasmid was purchased from Addgene.

\subsection{Immunoprecipitation and immunoblots}

Cells were washed with PBS and collected into lysis buffer (0.5\% Nonidet P-40 (Sigma) in $25 \mathrm{mM}$ Tris-HCl, pH 7.4, $150 \mathrm{mM} \mathrm{NaCl}, 1 \mathrm{mM}$ EDTA, $1 \mathrm{mM}$ PMSF, and $1 \mu \mathrm{M}$ PUGNAc with protease cocktail inhibitors). Lysates were sonicated, centrifuged to remove debris, and immunoprecipitations were performed with anti-HA antibody (12CA5 Roche Applied Science) or anti-Flag antibody (Sigma). The immunoprecipitates were washed and then eluted for immunoblot analysis. Samples were separated on SDS-polyacrylamide gels (Bio$\mathrm{Rad}$ ), and electroblotted to nitrocellulose (Bio-Rad). The immunoblots were first probed for $O$-GlcNAc RL-2 (Novus). Then, the immunoblots were stripped and reprobed with anti-HA (Covance) or anti-Flag (Sigma) antibodies to detect the protein levels.

\section{Results}

\subsection{Many kinases are in vitro substrates for OGT}

The protein array (HPFM3; Sigma) contains a set of 152 full-length human kinases printed in quadruplicate and fused to biotin-carboxyl carrier protein (BCCP). Thus, the printed kinases are not sterically or functionally hindered and are freely available as substrate for OGT. A c-Myc tag is incorporated into all protein kinases on the array slides for quantifying protein levels (Fig. 1A). Using UDP- $\left[{ }^{3} \mathrm{H}\right]-$ GlcNAc as the donor, we performed an in vitro OGT assay directly on the protein array slides to radiolabel any kinases that are good OGT substrates (Fig. 1B). BCCP-myc served as a negative control (yellow box in Fig. 2). We only analyzed the kinases with anti-c-myc-Cy3 signals higher than the lowest negative control spot and all four replicate spots displayed the same trend. As a result, we discarded results from 33 kinases that displayed lower anti-c-myc-Cy3 signals than negative controls (green boxes in Fig. 2), since low protein levels often lead to unreliable results. In addition, we discarded 11 kinases that contained background issues, interfering with proper signal measurement. Out of 108 kinases analyzed, we identified 42 kinases that were $O$ GlcNAcylated (blue boxes in Fig.2), representing 39\% of the total assayed. 66 kinases were 
not good in vitro substrates for OGT (red boxes in Fig.2). In our screen, 40 kinases previously unknown to be $O$-GlcNAcylated were identified as substrates for OGT. Two kinases previously shown to be $O$-GlcNAcylated, CaMKIV[4] and casein kinase II[23], were also identified in this assay (Table 1).

\subsection{Selected kinases are O-GIcNAcylated in vivo}

The $O$-GlcNAcylation levels (GL) of kinases were arbitrarily classified as very high (+++, $\mathrm{GL}>3.0)$; high $(++, 3.0>\mathrm{GL}>2.0)$; or positive $(+, 2.0>\mathrm{GL}>1.5)$. To validate the screen, we confirmed the $O$-GlcNAcylation of three selected kinases (one from each GL group), including protein kinase $\mathrm{C}$ zeta (PKC- $\zeta$ ), extracellular regulated kinase 5 (ERK-5), and ribosomal protein S6 kinase-like 1 (S6LK). We over-expressed these kinases in HEK293A cells and treated the cells with the $O$-GlcNAcase inhibitor NAG-thiazoline in order to increase total cellular $O$-GlcNAc levels. As expected, all three kinases immunoprecipitated were confirmed to be $O$-GlcNAcylated in vivo and the $O$-GlcNAc levels were responsive to NAG-thiazoline treatment (Figure 3).

\section{Discussion}

Dynamic PTMs control virtually all cellular events. $O$-GlcNAcylation and phosphorylation are perhaps amongst the two most abundant regulatory PTMs in cells and share many similarities. Both PTMs occur on Ser/Thr, are extremely dynamic, and can modulate protein function, interaction, and localization. In terms of site occupancy, $O$-GlcNAcylation and phosphorylation may block each other if occurring on the same site or at proximal sites via steric hindrance. Recently, our group showed that $O$-GlcNAcylation modulates Tyr608 phosphorylation in IRS-1[24], indicating that interplay between these PTMs at the substrate level is not limited to Ser and Thr residues. In addition, $O$-GlcNAcylation and tyrosine phosphorylation of prohibitin indicate a novel binary switch[25]. Under certain conditions, OGT associates with protein phosphatase 1 (PP1), indicating that a single enzyme complex can remove phosphate and add an $O$-GlcNAc residue on some proteins[26]. Alternatively, $O$-GlcNAcase interacts with CaMKIV upon ionomycin stimulation, providing an enzyme complex that can remove $O$-GlcNAc and add a phosphate[4]. During cytokinesis, OGT, $O$ GlcNAcase, Polo-kinase and PP1 form a protein complex[11].

$O$-GlcNAcylation and phosphorylation also appear to dynamically modulate the enzymes controlling each other's cycling on polypeptides. Both OGT and $O$-GlcNAcase are phosphorylated. While phosphorylation by the insulin receptor[27] and CaMKIV[28] activates OGT, the consequence of $O$-GlcNAcase phosphorylation remains unclear[29]. However, growing evidence indicates that regulation of kinases by OGT plays an important role in the crosstalk between these PTMs. Recently, we established that $O$-GlcNAcylation directly regulates the kinase activity of CaMKIV[4]. It is likely that similar results will be found for other kinases. Thus, we performed a screen to identify potential $O$-GlcNAcylated kinases. Of 108 kinases analyzed, we identify 42 kinases that are $O$-GlcNAcylated. Of note, two of the $42 O$-GlcNAcylated kinases identified are already known to be $O$-GlcNAcylated. We believe that the low number of previously known $O$-GlcNAcylated kinases is due to fact that individual kinases are not usually abundantly or ubiquitously expressed.

Although $O$-GlcNAcylation and phosphorylation are similar in several aspects, an important difference must be noted. While there are $\sim 500$ kinases and $\sim 150$ phosphatases that regulate phosphorylation in humans, only OGT and $O$-GlcNAcase catalyze $O$-GlcNAc cycling. Growing evidence indicate that OGT and $O$-GlcNAcase dynamically and specifically modify hundreds of proteins using interacting partners[30,31] to form transient complexes to regulate their specificity, in a process similar to that used by Ser/Thr phosphatases[32]. Taken together, we showed that $39 \%$ of kinases analyzed are $O$-GlcNAcylated in vitro. In 
addition, we validated our screen showing that three selected kinases are $O$-GlcNAcylated in vivo. The $O$-GlcNAcylation of other kinases should be confirmed in vivo and further studies should be performed in order to determine the biological functions of this PTM on each target. We also cannot rule out the negative samples in this screen as non-substrate kinases since other transient interactions with OGT may direct OGT activity toward these kinases.

While these 42 identified kinases belong to many different cellular pathways, the majority of them are also related to cancer. Several groups have recently published reports showing that $O$-GlcNAcase is down regulated, while $O$-GlcNAc and OGT are elevated in various cancers when compared to normal tissues[33-36]. Our results indicate that the crosstalk of these two major PTMs is very complex and opens a vast field to explore the importance of kinase $O$ GlcNAcylation in different cell signaling events and metabolic diseases as cancer, diabetes, and Alzheimer's disease.

\section{Acknowledgments}

We thank Drs. Kaoru Sakabe, Chad Slawson, and other members of the G.W.H. laboratory for helpful discussions and Isadora Oliveira for help with figure designs. This work was supported by National Institutes of Health Grants R01 DK61671, R01 CA42486, PO1 HL107153 and contract NO1-HV-28180 (to G.W.H.).

\section{References}

1. Hart GW, Housley MP, Slawson C. Cycling of O-linked beta-N-acetylglucosamine on nucleocytoplasmic proteins. Nature. 2007; 446:1017-1022. [PubMed: 17460662]

2. Zeidan Q, Hart GW. The intersections between O-GlcNAcylation and phosphorylation: implications for multiple signaling pathways. J Cell Sci. 2010; 123:13-22. [PubMed: 20016062]

3. Hart GW, Slawson C, Ramirez-Correa G, Lagerlof O. Cross talk between O-GlcNAcylation and phosphorylation: roles in signaling, transcription, and chronic disease. Annu Rev Biochem. 2011; 80:825-858. [PubMed: 21391816]

4. Dias WB, Cheung WD, Wang Z, Hart GW. Regulation of calcium/calmodulin-dependent kinase IV by O-GlcNAc modification. J Biol Chem. 2009; 284:21327-21337. [PubMed: 19506079]

5. Yang WH, Kim JE, Nam HW, Ju JW, Kim HS, Kim YS, Cho JW. Modification of p53 with Olinked N-acetylglucosamine regulates p53 activity and stability. Nat Cell Biol. 2006; 8:1074-1083. [PubMed: 16964247]

6. Gewinner C, Hart G, Zachara N, Cole R, Beisenherz-Huss C, Groner B. The coactivator of transcription CREB-binding protein interacts preferentially with the glycosylated form of Stat5. J Biol Chem. 2004; 279:3563-3572. [PubMed: 14597631]

7. Dauphinee SM, Ma M, Too CK. Role of O-linked beta-N-acetylglucosamine modification in the subcellular distribution of alpha4 phosphoprotein and $\mathrm{Sp} 1$ in rat lymphoma cells. J Cell Biochem. 2005; 96:579-588. [PubMed: 16052526]

8. Gao Y, Miyazaki J, Hart GW. The transcription factor PDX-1 is post-translationally modified by Olinked $\mathrm{N}$-acetylglucosamine and this modification is correlated with its DNA binding activity and insulin secretion in min6 beta-cells. Arch Biochem Biophys. 2003; 415:155-163. [PubMed: 12831837]

9. O'Donnell N, Zachara NE, Hart GW, Marth JD. Ogt-dependent X-chromosome-linked protein glycosylation is a requisite modification in somatic cell function and embryo viability. Mol Cell Biol. 2004; 24:1680-1690. [PubMed: 14749383]

10. Dias WB, Hart GW. O-GlcNAc modification in diabetes and Alzheimer's disease. Mol Biosyst. 2007; 3:766-772. [PubMed: 17940659]

11. Slawson C, Copeland RJ, Hart GW. O-GlcNAc signaling: a metabolic link between diabetes and cancer? Trends Biochem Sci. 2010; 35:547-555. [PubMed: 20466550]

12. Slawson C, Hart GW. Dynamic interplay between O-GlcNAc and O-phosphate: the sweet side of protein regulation. Curr Opin Struct Biol. 2003; 13:631-636. [PubMed: 14568619] 
13. Wang Z, Gucek M, Hart GW. Cross-talk between GlcNAcylation and phosphorylation: sitespecific phosphorylation dynamics in response to globally elevated O-GlcNAc. Proc Natl Acad Sci U S A. 2008; 105:13793-13798. [PubMed: 18779572]

14. Luo B, Soesanto Y, McClain DA. Protein modification by O-linked GlcNAc reduces angiogenesis by inhibiting Akt activity in endothelial cells. Arterioscler Thromb Vasc Biol. 2008; 28:651-657. [PubMed: 18174452]

15. Kang ES, et al. O-GlcNAc modulation at Akt1 Ser473 correlates with apoptosis of murine pancreatic beta cells. Exp Cell Res. 2008; 314:2238-2248. [PubMed: 18570920]

16. Gandy JC, Rountree AE, Bijur GN. Akt1 is dynamically modified with O-GlcNAc following treatments with PUGNAc and insulin-like growth factor-1. FEBS Lett. 2006; 580:3051-3058. [PubMed: 16684529]

17. Robles-Flores M, Melendez L, Garcia W, Mendoza-Hernandez G, Lam TT, Castaneda-Patlan C, Gonzalez-Aguilar H. Posttranslational modifications on protein kinase c isozymes. Effects of epinephrine and phorbol esters. Biochim Biophys Acta. 2008; 1783:695-712. [PubMed: 18295358]

18. Manning G, Whyte DB, Martinez R, Hunter T, Sudarsanam S. The protein kinase complement of the human genome. Science. 2002; 298:1912-1934. [PubMed: 12471243]

19. Stoevesandt O, Taussig MJ, He M. Protein microarrays: high-throughput tools for proteomics. Expert Rev Proteomics. 2009; 6:145-157. [PubMed: 19385942]

20. Lazarus MB, Nam Y, Jiang J, Sliz P, Walker S. Structure of human O-GlcNAc transferase and its complex with a peptide substrate. Nature. 2011; 469:564-567. [PubMed: 21240259]

21. Gross BJ, Kraybill BC, Walker S. Discovery of O-GlcNAc transferase inhibitors. J Am Chem Soc. 2005; 127:14588-14589. [PubMed: 16231908]

22. Cheung WD, Hart GW. AMP-activated protein kinase and p38 MAPK activate O-GlcNAcylation of neuronal proteins during glucose deprivation. J Biol Chem. 2008; 283:13009-13020. [PubMed: 18353774]

23. Iyer SP, Hart GW. Roles of the tetratricopeptide repeat domain in O-GlcNAc transferase targeting and protein substrate specificity. J Biol Chem. 2003; 278:24608-24616. [PubMed: 12724313]

24. Whelan SA, Dias WB, Thiruneelakantapillai L, Lane MD, Hart GW. Regulation of insulin receptor substrate 1 (IRS-1)/AKT kinase-mediated insulin signaling by O-Linked beta-Nacetylglucosamine in 3T3-L1 adipocytes. J Biol Chem. 2010; 285:5204-5211. [PubMed: 20018868]

25. Ande SR, Moulik S, Mishra S. Interaction between O-GlcNAc modification and tyrosine phosphorylation of prohibitin: implication for a novel binary switch. PLoS One. 2009; 4:e4586. [PubMed: 19238206]

26. Wells L, Kreppel LK, Comer FI, Wadzinski BE, Hart GW. O-GlcNAc transferase is in a functional complex with protein phosphatase 1 catalytic subunits. J Biol Chem. 2004; 279:38466-38470. [PubMed: 15247246]

27. Whelan SA, Lane MD, Hart GW. Regulation of the O-linked beta-N-acetylglucosamine transferase by insulin signaling. J Biol Chem. 2008; 283:21411-21417. [PubMed: 18519567]

28. Song M, Kim HS, Park JM, Kim SH, Kim IH, Ryu SH, Suh PG. o-GlcNAc transferase is activated by CaMKIV-dependent phosphorylation under potassium chloride-induced depolarization in NG-108-15 cells. Cell Signal. 2008; 20:94-104. [PubMed: 18029144]

29. Beausoleil SA, et al. Large-scale characterization of HeLa cell nuclear phosphoproteins. Proc Natl Acad Sci U S A. 2004; 101:12130-12135. [PubMed: 15302935]

30. Cheung WD, Sakabe K, Housley MP, Dias WB, Hart GW. O-linked beta-Nacetylglucosaminyltransferase substrate specificity is regulated by myosin phosphatase targeting and other interacting proteins. J Biol Chem. 2008; 283:33935-33941. [PubMed: 18840611]

31. Yang X, et al. Phosphoinositide signalling links O-GlcNAc transferase to insulin resistance. Nature. 2008; 451:964-969. [PubMed: 18288188]

32. Cohen PT. Protein phosphatase 1--targeted in many directions. J Cell Sci. 2002; 115:241-256. [PubMed: 11839776] 
33. Caldwell SA, Jackson SR, Shahriari KS, Lynch TP, Sethi G, Walker S, Vosseller K, Reginato MJ. Nutrient sensor O-GlcNAc transferase regulates breast cancer tumorigenesis through targeting of the oncogenic transcription factor FoxM1. Oncogene. 2010; 29:2831-2842. [PubMed: 20190804]

34. Lynch TP, Reginato MJ. O-GlcNAc transferase: a sweet new cancer target. Cell Cycle. 2011; 10:1712-1713. [PubMed: 21519190]

35. Mi W, Gu Y, Han C, Liu H, Fan Q, Zhang X, Cong Q, Yu W. O-GlcNAcylation is a novel regulator of lung and colon cancer malignancy. Biochim Biophys Acta. 2011; 1812:514-519. [PubMed: 21255644]

36. Krzeslak A, Forma E, Bernaciak M, Romanowicz H, Brys M. Gene expression of O-GlcNAc cycling enzymes in human breast cancers. Clin Exp Med. 2012; 12:61-65. [PubMed: 21567137] 


\section{Highlights}

- We performed an OGT assay using an array of 152 human protein kinases as substrate.

- We identified 42 O-GlcNAcylated protein kinases.

- Two of identified kinases have previously been demonstrated to be OGlcNAcylated.

- We confirmed three of the newly identified kinases - PKC- $\zeta$, ERK-5, and S6LK. 
A B
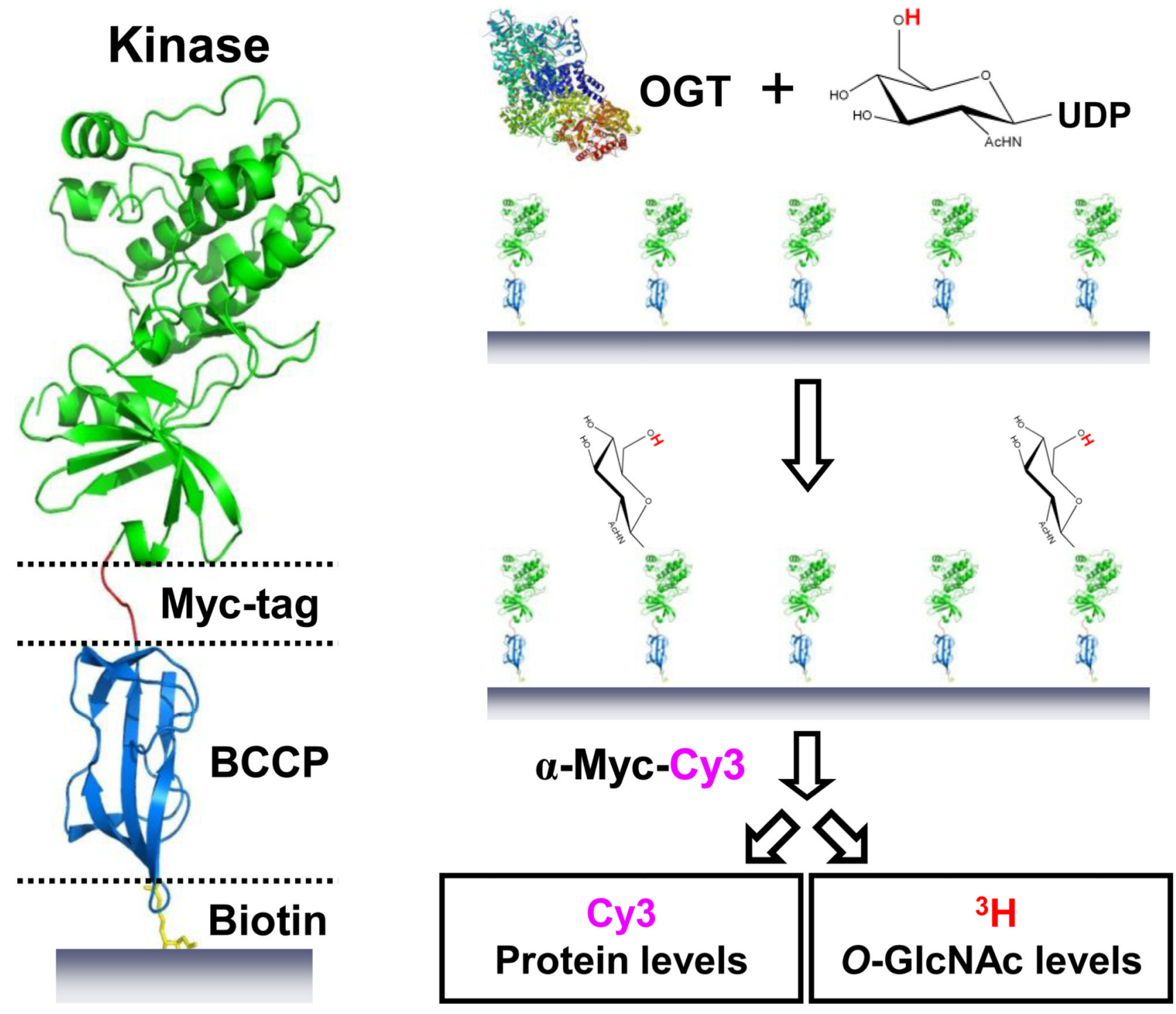

Figure 1.

Strategy to identify $O$-GlcNAcylation of human kinases using recombinant OGT. (A) All kinases were fused to a carrier protein and present a myc-tag for quantifying protein levels. (B) The protein array containing 152 kinases spotted in quadruplicate was incubated with recombinant human OGT and UDP- $\left[{ }^{3} \mathrm{H}\right]-$ GlcNAc. After washing, the array was incubated with anti myc-Cy3 antibody to quantify the protein levels and then exposed to a ${ }^{3} \mathrm{H}$-sensitive storage phosphor screen to quantify the $O$-GlcNAcylation levels. 


\section{Protein levels}

\section{O-GIcNAc levels}
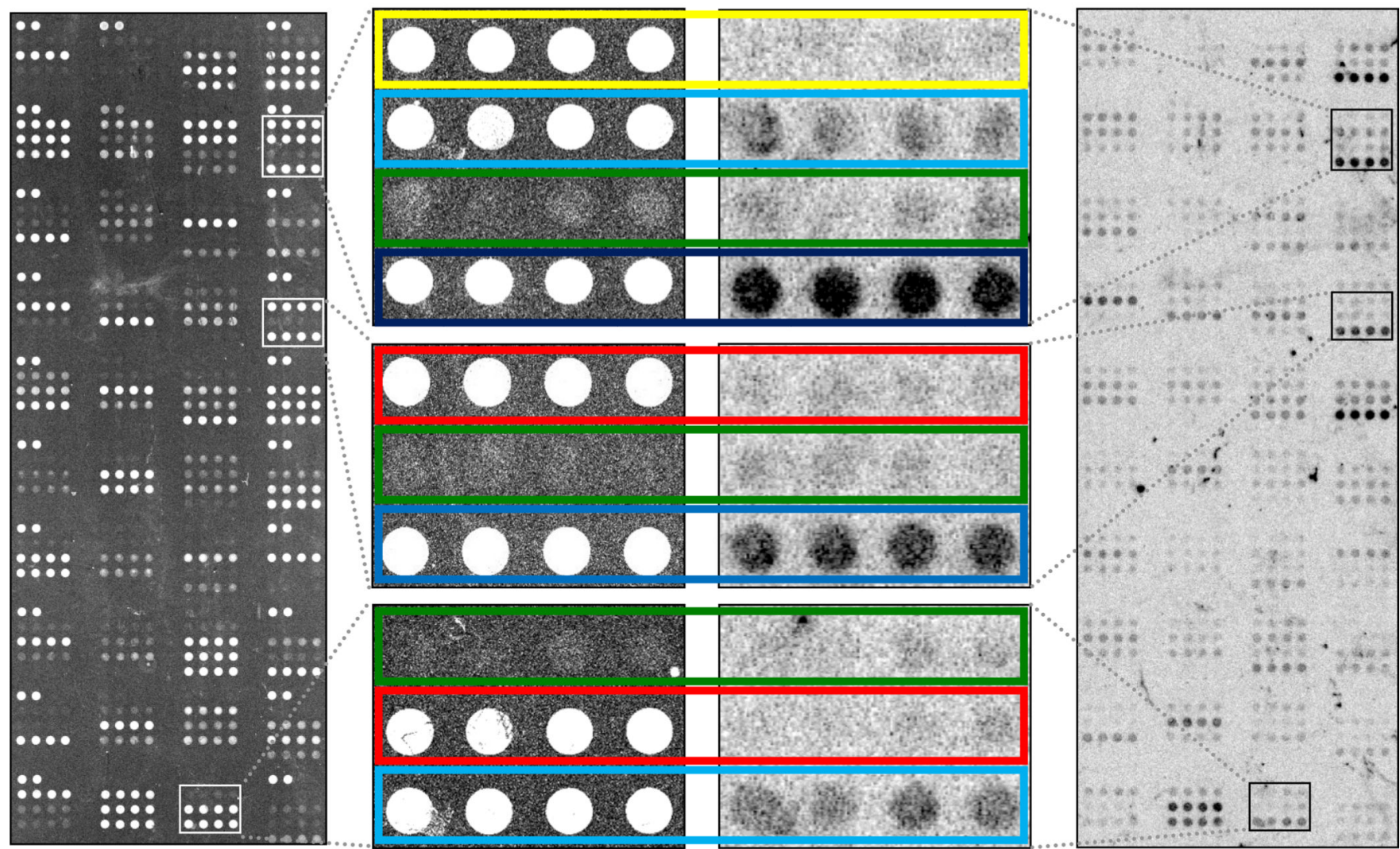

Negative Control (BCCP-myc)

O-GIcNAcylated Kinase (+)

Kinase Levels Below Minimum

Non-O-GIcNAcylated Kinase

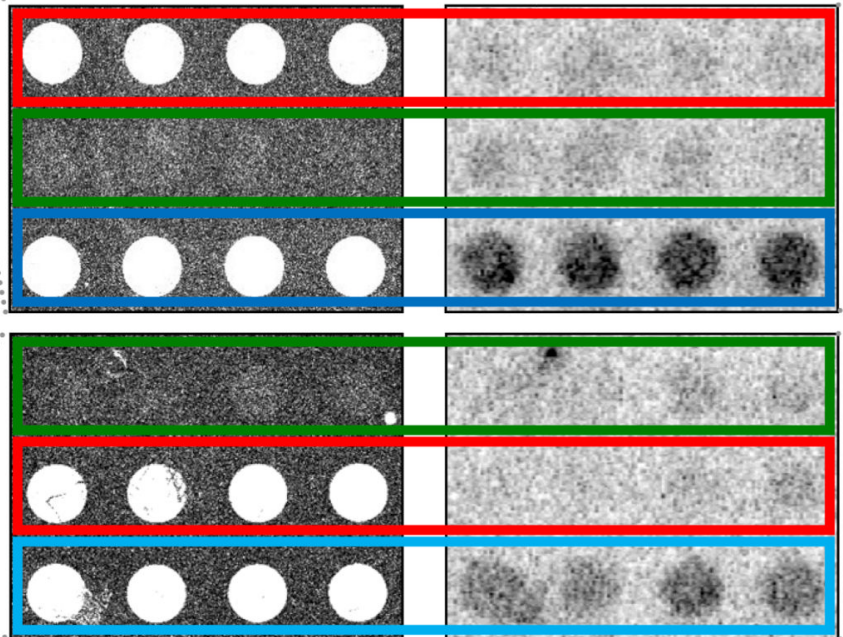

$\because 6$. bated

Non-O-GlcNAcylated Kinase

Figure 2.

OGT modifies several kinases in vitro. The left panel shows the protein levels after scanning the array for $\mathrm{Cy} 3$ labeling. The right panel shows the $O$-GlcNAcylation levels after scanning the array for ${ }^{3} \mathrm{H}$ labeling. The enlarged regions show the $O$-GlcNAcylation and protein levels of a few of the kinases in detail. 

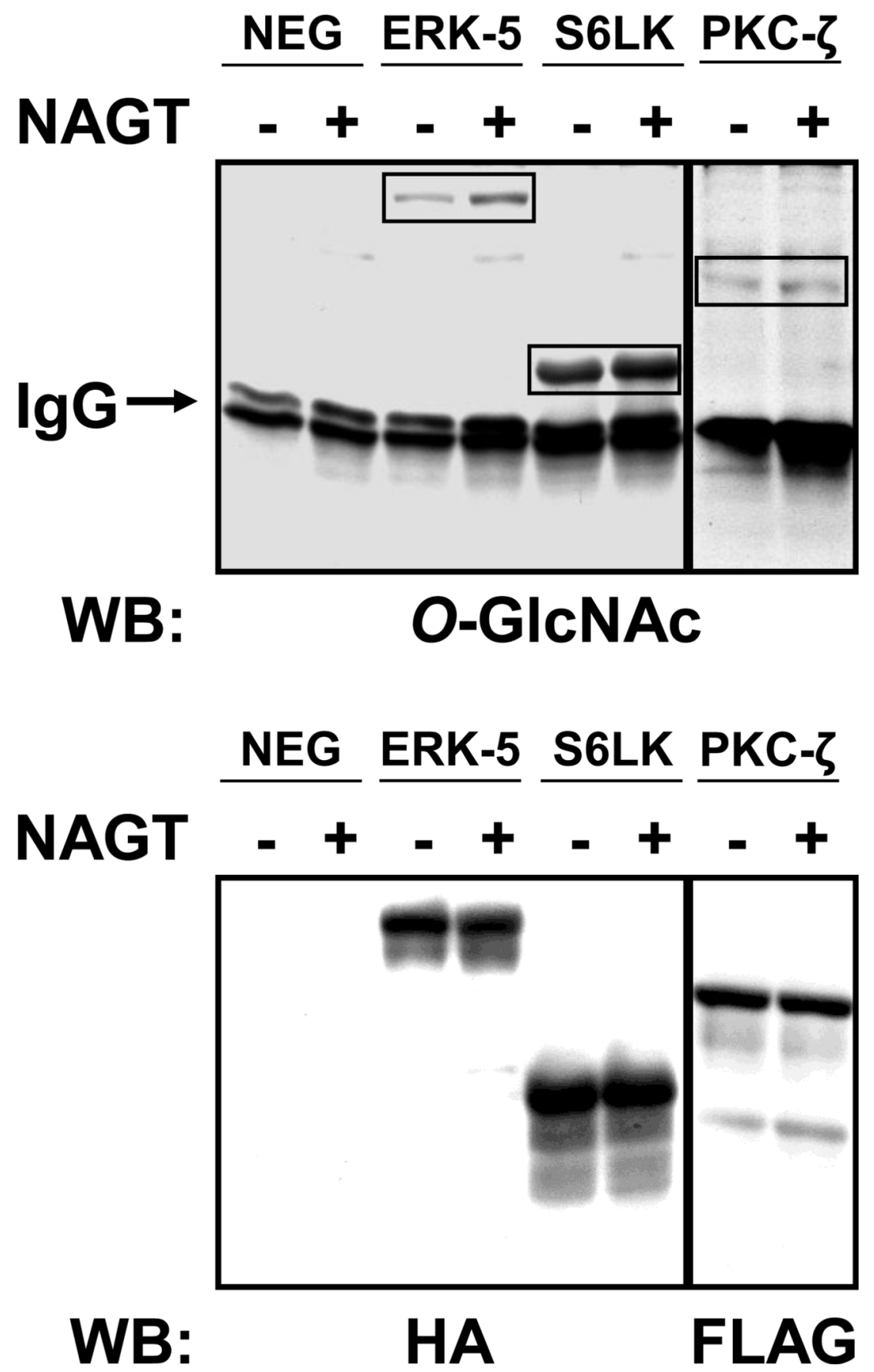

Figure 3.

Selected kinases are $O$-GlcNAcylated in vivo. Lysates from HEK293 cells transfected with empty HA plasmid, ERK5-HA, S6LK1-HA, PKC- $\zeta$-Flag were imunoprecipitated for HA or Flag tags. When indicated, the cells were treated with NAG-thiazole overnight. 
Table 1

List of identified GlcNAcylated kinases.

\begin{tabular}{|c|c|c|c|}
\hline Kinase & $\begin{array}{l}\text { NCBI } \\
\text { Protein }\end{array}$ & GlcNAcylation/protein & $\begin{array}{c}\text { Relative } \\
\text { GlcNAcylation } a\end{array}$ \\
\hline cell cycle related kinase & AAH02655 & $6.97+/-0.077$ & +++ \\
\hline H11 & AAH02673 & $4.26+/-0.007$ & +++ \\
\hline ribosomal protein S6 kinase-like 1 & AAH04540 & $3.97+/-0.023$ & +++ \\
\hline AAK1 & AAH02695 & $3.71+/-0.038$ & +++ \\
\hline ezrin-binding partner PACE-1 & AAH14662 & $3.07+/-0.042$ & +++ \\
\hline PCTAIRE protein kinase 1 & AAH06190 & $2.51+/-0.038$ & ++ \\
\hline casein kinase 2 & AAH11668 & $2.50+/-0.024$ & ++ \\
\hline ERK-5 & AAH30134 & $2.47+/-0.151$ & ++ \\
\hline serine/threonine kinase $17 \mathrm{~b}$ & AAH 16040 & $2.38+/-0.109$ & ++ \\
\hline PTK9 protein tyrosine kinase 9 & AAH22344 & $2.23+/-0.025$ & ++ \\
\hline Chromosome 20 orf 97 & AAH27484 & $2.19+/-0.020$ & ++ \\
\hline CaMKIV & AAH16695 & $2.16+/-0.123$ & ++ \\
\hline MAP3K6 & AAH15914 & $2.11+/-0.084$ & ++ \\
\hline p21(CDKN1A)-activated kinase 4 & AAH02921 & $2.07+/-0.072$ & ++ \\
\hline pyruvate kinase; liver and RBC & AAH25737 & $1.95+/-0.025$ & + \\
\hline serine/threonine kinase 33 & AAH31231 & $1.94+/-0.086$ & + \\
\hline serine/threonine kinase 11 & AAH07981 & $1.90+/-0.282$ & + \\
\hline PX domain containing ser/thr kinase & AAH14479 & $1.82+/-0.064$ & + \\
\hline SFRS protein kinase 1 & AAH38292 & $1.78+/-0.102$ & + \\
\hline SRC & AAH11566 & $1.73+/-0.073$ & + \\
\hline AURKB & AAH00442 & $1.72+/-0.041$ & + \\
\hline RIO kinase 2 & AAH00953 & $1.69+/-0.085$ & + \\
\hline Protein kinase D2 & AAH25307 & $1.67+/-0.043$ & + \\
\hline STK24 & AAH35578 & $1.67+/-0.057$ & + \\
\hline STK25 & AAH-7852 & $1.65+/-0.025$ & + \\
\hline MAP2K3 & AAH32478 & $1.64+/-0.024$ & + \\
\hline SNARK & AAH17306 & $1.64+/-0.189$ & + \\
\hline serine/threonine kinase 22D & AAH 22515 & $1.62+/-0.042$ & + \\
\hline PLK & AAH02369 & $1.61+/-0.076$ & + \\
\hline Serine/threonine kinase 16 & AAH02618 & $1.60+/-0.051$ & + \\
\hline RIO kinase 3 & AAH39729 & $1.60+/-0.051$ & + \\
\hline CaMKK beta & AAH19070 & $1.60+/-0.068$ & + \\
\hline Pim-1 oncogene & AAH20224 & $1.59+/-0.132$ & + \\
\hline $\mathrm{CDK} 2$ & AAH03065 & $1.58+/-0.066$ & + \\
\hline MAPK 14 & AAH00092 & $1.58+/-0.086$ & + \\
\hline v-aht-homolog 1 & AAH00479 & $1.54+/-0.071$ & + \\
\hline Bromodomain containing 3 & AAH32124 & $1.54+/-0.098$ & + \\
\hline DYRK2 & AAH05809 & $1.53+/-0.023$ & + \\
\hline
\end{tabular}




\begin{tabular}{lccc}
\hline Kinase & $\begin{array}{c}\text { NCBI } \\
\text { Protein }\end{array}$ & GlcNAcylation/protein & $\begin{array}{c}\text { Relative } \\
\text { GlcNAcylation } \boldsymbol{a}\end{array}$ \\
\hline Protein kinase C; zeta & AAH08058 & $1.51+/-0.072$ & + \\
\hline
\end{tabular}

Kinases in bold font were selected for in vivo confirmation.

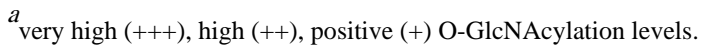

